\title{
Querion do couro cabeludo - A propósito de um caso clínico
}

Barbara Anahory*, Patrícia Santos*, Marta Borges*

\section{RESUMO}

Introdução: A tinea capitis, considerada a dermatofitose mais comum em idade pediátrica, pode ter várias apresentações clínicas, desde uma descamação não inflamatória até uma severa erupção pustular designada de Querion de Celsi. Esta última pode evoluir para uma alopécia cicatricial, situação que pode ser evitada com o diagnóstico e tratamento atempados da doença.

Descrição do Caso: Criança do sexo masculino, 12 anos e raça caucasiana, sem antecedentes patológicos de relevo, foi observada em Novembro de 2011, na consulta aberta da unidade de cuidados de saúde primários da área de residência, por placa supurativa da região occipitoparietal esquerda, com cerca de cinco centímetros de diâmetro, dolorosa e com cinco meses de evolução. Admitida a hipótese de diagnóstico de abcesso do couro cabeludo, foi medicada com antibioterapia sistémica. Cerca de um mês depois, em Dezembro de 2011, por agravamento progressivo da lesão, recorreu ao serviço de urgência do hospital, altura em que foi pedida a colaboração da Dermatologia. Após o estabelecimento do diagnóstico de Querion de Celsi, foi instituída terapêutica com terbinafina ( $125 \mathrm{mg} / \mathrm{dia}$ ) e champô de cetoconazol, durante três meses, com cura da infecção fúngica e alopécia cicatricial como sequela.

Comentário: Pretende-se alertar para a necessidade do reconhecimento precoce destas lesões, permitindo instituir o tratamento adequado, de forma a evitar a alopécia cicatricial.

Palavras-chave: Tinea capitis; Kerion Celsi; Alopecia.

\section{INTRODUÇÃO}

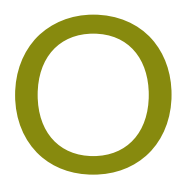

amplo diagnóstico diferencial das lesões do couro cabeludo inclui patologias como Dermatite Seborreica, Alopecia Areata, Tricolomania, Psoríase, Foliculite Decalvante ou Pioderma. Assim, uma história clínica e exame objectivo cautelosos são essenciais, devendo sempre excluir-se uma infecção fúngica que, se tardiamente diagnosticada e tratada, pode evoluir para uma alopécia cicatricial como sequela. ${ }^{4,5} \mathrm{~A}$ tinea capitis é muito contagiosa, podendo originar epidemias, pelo que o seu diagnóstico precoce permite a implementação de medidas preventivas, evitando o contágio e aparecimento de portadores assintomáticos. ${ }^{3,4}$

A tinea capitis causada por fungos do género $\mathrm{Mi}$ crosporum e Trichophyton é a dermatofitose mais co-

*Interna do $2 .^{\circ}$ ano de Medicina Geral e Familiar, Unidade de Saúde de Ilha de São Miguel, Ponta Delgada, Açores

***Diretora do Serviço de Dermatologia, Hospital do Divino Espírito Santo, E.P.E., Ponta Delgada, Açores

***Assistente de Medicina Geral e Familiar, Unidade de Saúde de Itha de São Miguel, Ponta Delgada, Açores mum da infância, particularmente entre os 6 e 10 anos, podendo ter várias apresentações clínicas, desde uma descamação não inflamatória até uma severa erupção pustular com alopécia, designada de Querion de Celsi. $^{1,2,4}$

O presente caso clínico pretende alertar para uma situação de difícil diagnóstico mimetizando inúmeras patologias, com necessidade de tratamento atempado.

\section{DESCRIÇÃO DO CASO}

Serafim, sexo masculino, raça caucasiana, 12 anos, natural dos Açores, frequenta o quarto ano de escolaridade, com mau aproveitamento escolar. Sem antecedentes pessoais de relevo.

Pertence a uma família alargada, abandonado pela mãe aos três anos de idade, nunca conheceu o pai. Foi criado pela bisavó e avó materna, de 86 e 59 anos, respectivamente, com as quais tem uma boa relação. A relação com o irmão mais velho três anos é bastante próxima, o que contrasta com a relação distante que tem com os tios maternos alcoólicos. 
Esta é uma família pertencente à classe social baixa de acordo com a classificação de Graffar e de alto risco de acordo com a escala de Segóvia-Dreyer.

Em Novembro de 2011, o doente recorreu à consulta aberta da unidade de cuidados de saúde primários da área de residência por placa supurativa do couro cabeludo, com cerca de cinco meses de evolução, tendo sido diagnosticado abcesso do couro cabeludo, realizada drenagem da lesão e medicado com antisséptico tópico e antibioterapia sistémica.

Cerca de um mês depois, o progressivo agravamento da lesão levou a que recorresse ao Serviço de Urgência hospitalar. Ao exame objectivo apresentava na região occipitoparietal esquerda uma placa supurativa com cerca de $5 \mathrm{~cm}$ de maior diâmetro, dolorosa e com alopécia associada (Figura 1). De realçar a evidência de cuidados de higiene precários. Na história clínica revelou que tinha contacto frequente com animais, nomeadamente cães e vacas.

Foi observado por Dermatologia, que diagnosticou Querion de Celsi e medicou com terbinafina oral (125 $\mathrm{mg} / \mathrm{dia})$ e champô de cetoconazol para lavagens diárias. Foram aconselhadas medidas preventivas como desinfecção de escovas, chapéus e outros objectos que tenham estado em contacto com a lesão. Foi aconselhada a observação dos animais pelo veterinário para avaliar a possibilidade de serem eventuais portadores da infecção fúngica.

A 11/01/2012, em consulta de Dermatologia Pediátrica, a criança apresentava franca melhoria clínica, embora mantivesse escassas lesões pustulosas e alopécia do couro cabeludo. Nessa altura decidiu-se manter a medicação prescrita por mais um mês.

A 29/02/2012, após ter cumprido 12 semanas de tratamento com antifúngico oral, regressou à consulta com cura total da infecção fúngica, mantendo, no entanto, zona de alopécia cicatricial. Optou-se por manter as lavagens com champô de cetoconazol.

Na consulta de 02/05/2012, verificou-se remissão parcial da área de alopécia, pelo que se decidiu iniciar tratamento com minoxidil tópico a 5\%, para aplicar diariamente na zona de alopécia.

A 08/08/2012, em nova consulta de Dermatologia, verificou-se que a criança manteve a mesma área de alopécia, tendo sido possível apurar, junto de familiares, que a medicação tópica (minoxidil a 5\%) não foi

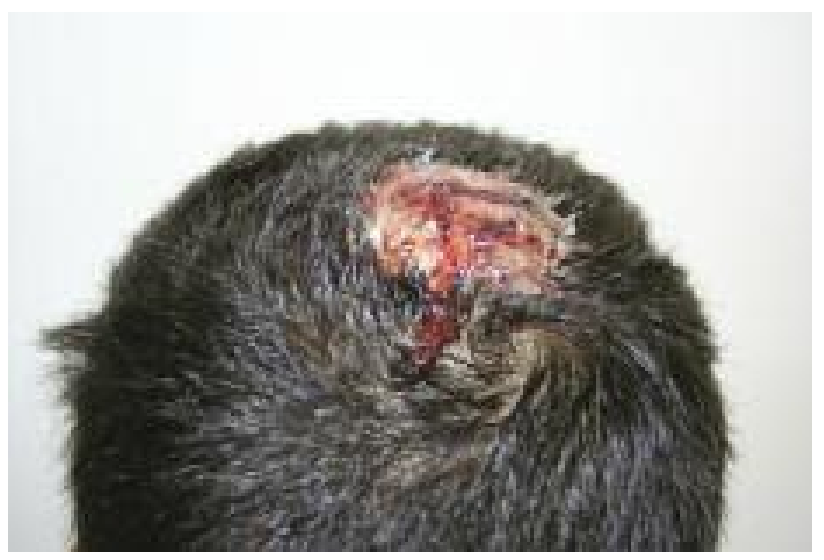

Figura 1. Querion de Celsi do couro cabeludo.

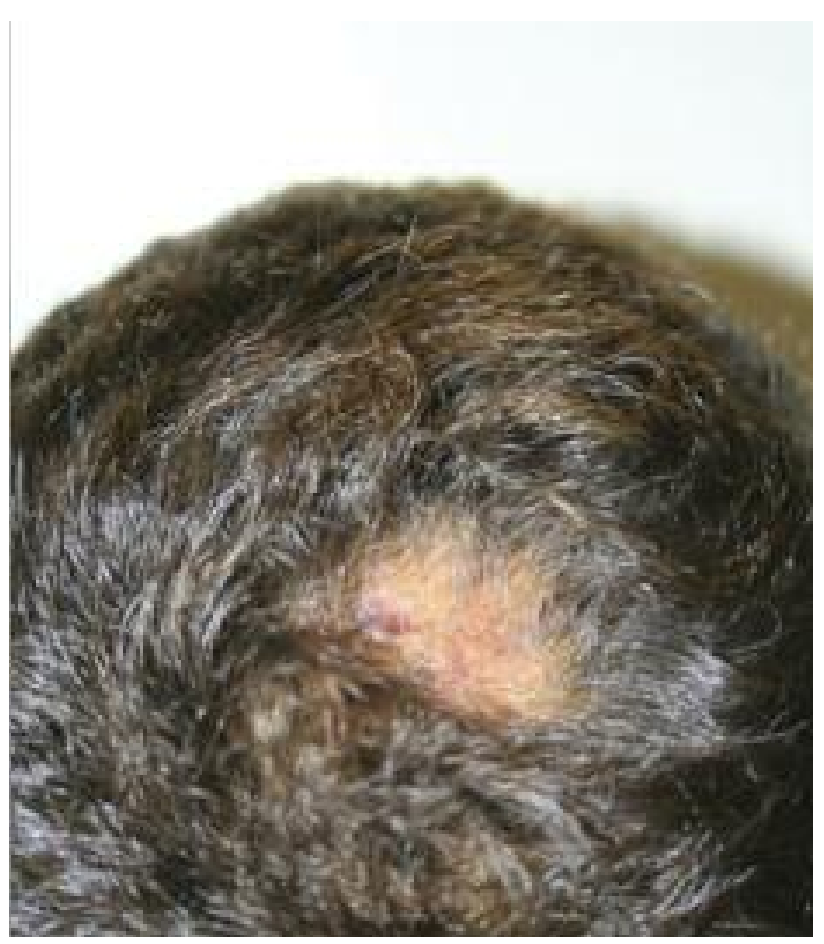

Figura 2. Alopécia Cicatricial do couro cabeludo.

efectuada por impossibilidade económica. Assumiu-se o diagnóstico de alopécia cicatricial (Figura 2) e manteve-se seguimento na consulta de Dermatologia, de modo a avaliar a evolução.

\section{COMENTÁRIOS}

A tinea capitis é uma infecção fúngica com um impacto social marcado, causando grande preocupação e 
levando à restrição de actividades sociais e da frequência escolar pela criança infectada. ${ }^{3}$

Pode assumir uma forma não inflamatória ou tonsurante e outra inflamatória ou Querion. ${ }^{6} \mathrm{O}$ caso aqui apresentando é referente à última entidade, uma tinea capitis inflamatória dos folículos do couro cabeludo e pele, habitualmente causada por fungos geofílicos e zoofílicos, mas também antropofílicos.

A história clínica de contacto frequente com animais deve, por isso, ser sempre questionada, o que poderá levar à suspeição diagnóstica de tinea capitis.

A apresentação clínica supurativa do Querion leva a que esta lesão seja, muitas vezes, erroneamente diagnosticada como uma infecção bacteriana, tal como no caso apresentado, o que levou a uma ineficaz conduta terapêutica inicial, contribuindo para o agravamento da situação clínica e atraso na sua resolução. ${ }^{7}$

É, por isso, objectivo deste caso alertar para a necessidade do reconhecimento precoce destas lesões, permitindo que seja instituído o adequado tratamento, evitando a alopécia cicatricial, que pode advir do seu diagnóstico tardio.

Neste caso, a procura tardia dos cuidados de saúde, associadas à precariedade dos cuidados de higiene e à baixa diferenciação sócio-cultural, também terá contribuído para a difícil resolução do quadro clinico.

A confirmação diagnóstica é, habitualmente, feita através do exame micológico directo e cultural, podendo ser auxiliado pelo uso da luz de Wood. ${ }^{7}$ Neste caso, devido ao elevado índice de suspeição fornecido pelas características da lesão, associada a história de contacto com animais, foi feito o diagnóstico clínico, pelo que não se considerou fundamental a colheita do cabelo para exame micológico cultural e isolamento do agente causal. Situação que é aliás de difícil prática na actividade diária do Médico de Dermatologia, tal como na do Médico de Família.

Ao contrário, do que acontece com as restantes dermatofitoses, na tinea capitis a monoterapia com antifúngicos tópicos não é eficaz, uma vez que, estes não penetram no cabelo, por isso, se iniciou tratamento tópico e oral verificando-se melhoria evidente, com resolução da lesão., ${ }^{6,8}$

Recomenda-se para o tratamento tópico champô de cetoconazol ou sulfureto de selénio, associando-se solutos desinfectantes de camomila ou permanganato potássico a $1 / 10.000$ nas lesões muito supurativas, pela sua acção secante e desinfectante. ${ }^{4,6,9}$

A griseofulvina é o antifúgico oral de escolha, pela escassez de efeitos secundários. Contudo, não se encontra comercializado em Portugal. ${ }^{6}$

O fluconazol, itraconazol e a terbinafina são opções terapêuticas também eficazes no tratamento da tinea capitis em crianças. ${ }^{3,89}$ No entanto, actualmente, apenas o fluconazol está aprovado pelo Infarmed para uso em idade pediátrica. ${ }^{10}$

As doses recomendadas são, para o fluconazol, de $6 \mathrm{mg} / \mathrm{kg} /$ dia durante 3 a 6 semanas, para o itraconazol, de $5 \mathrm{mg} / \mathrm{kg} /$ dia durante 4 a 8 semanas e, para a terbinafina, ajustadas de acordo com o peso da criança, ou seja, de 62,5 mg/dia (10-20 kg), 125mg/dia (20-40 kg) e $250 \mathrm{mg} / \mathrm{dia}(>40 \mathrm{~kg}))^{4,8}$

A implementação de medidas preventivas é igualmente importante, tais como a desinfecção de escovas, chapéus ou outros objectos que tenham estado em contacto com a lesão, como aliás, foi recomendado ao doente. ${ }^{2,4,8,9}$ Os contactos escolares e domiciliares da criança devem ser examinados e tratados preventivamente com champô de cetoconazol ou sulfureto de selénio, permitindo a detecção de casos frustes de tinha do couro cabeludo e a irradicação de portadores assintomáticos. ${ }^{2,4,8,9}$

Sendo a tinea capitis uma dermatofitose frequente na criança, o Médico de Família deve estar apto a fazer a sua identificação precoce, instituindo tratamento adequado, de forma a evitar a evolução da doença e a sua evolução para alopécia cicatricial, situação que pode imprimir problemas de auto-estima, com repercussões no desenvolvimento psico-social da criança.

\section{REFERÊNCIAS BIBLIOGRÁFICAS}

1. Möhrenschlager $M$, Seidl HP, Ring J, et al. Pediatric tinea capitis: recognition and management. Am J Clin Dermatol 2005; 6 (4): 203$-13$.

2. Wolff K, Johnson RA, Suurmond D. Fitzpatrick Dermatologia:Atlas e Texto. $5^{a}$ ed. Rio de Janeiro: McGraw Hill; 2006. p.707-12.

3. Hernández T, Machado S, Carvalho S, et al. Tinhas do Couro Cabeludo na Idade Pediátrica. Nascer e Crescer 2004; 13 (1): 23-6.

4. Bolognia JL, Jorizzo JL, Rapini RP. Dermatology. St. Louis: Mosby. 2003. p. 1179-85.

5. Goldstein AO, Goldstein BG.Approach to the patient with a scalp eruption.Uptodate [Internet]. 2012 May. Disponível em: http://www.uptodate.com [acedido em 08/08/2012].

6. Gutiérres EQ, Collantes DS. Dermatologia Básica em Medicina Fami- 
liar. Lisboa: Lidel; 2011. p. 198-205.

7. Peixoto $A B$, Novis $C F$, Vilela $G M$, Lerer $C$. Kerion: a importância da sua diferenciação com infecção bacteriana do couro cabeludo: relato de caso. Rev Bras Cln Med 2012 mai-jun; 10 (3): 243-5.

8. Gupta AK, Cooper EA. Update in antifungal therapy of dermatophytosis. Mycopathologia 2008 Nov-Dec; 166 (5-6): 353-67.

9. Goldstein AO, Goldstein BG. Dermatophyte (tinea) infections. Uptodate [Internet]. 2012 June. Disponível em: http://www.uptodate.com [acedido em 08/08/2012].

10. Ministério da Saúde, Infarmed. Prontuário terapêutico. Lisboa: Infarmed; 2011. p. 53-8.

\section{CONFLITO DE INTERESSES:}

As autoras declaram não ter conflito de interesses.

\section{ENDEREÇO PARA CORRESPONDÊNCIA}

Barbara Bettencourt Anahory

Rua Padre Domingos S Costa

9500-614 Livramento

E-mail: barbaraanahory@gmail.com

Recebido em 10/12/2012

Aceite para publicação em 18/09/2013

\section{ABSTRACT}

\section{KERION CELSI - A CASE REPORT}

Introduction: Tinea capitis is the most common form of ringworm infection in childhood. It can have various clinical presentations, ranging from non-inflammatory scaling to a severe pustular rash called Kerion celsi. This may heal with scarring alopecia, but it can be avoided if there is timely diagnosis and treatment of the disease.

Case description: A 12 year-old Caucasian male with no significant past medical history was seen in November 2011 in the emergency department of his local health centre. He had suppurative scaling of the scalp in the left occipito-parietal region, of five centimeters in diameter. It was painful and had been present for five months. A diagnosis of a scalp abscess was made. He was treated with systemic antibiotics. Due to progressive worsening of the lesion, in December 2011 he went to the emergency department of a local hospital, where a dermatology consultation was requested. He was diagnosed with Kerion celsi, and treatment with terbinafine $(125 \mathrm{mg} /$ day $)$ and ketoconazole shampoo was started. The child was treated for three months with cure of the fungal infection, but scarring alopecia remained.

Comment: Early recognition of this lesion permits proper treatment in order to prevent scarring alopecia.

Keywords: Tinea capitis; Kerion celsi; Alopecia. 